\title{
Clinical and histopathological analysis of oral Squamous cell carcinoma of young patients in Mashhad, Iran: A retrospective study and review of literatures
}

\author{
Farnaz Falaki ${ }^{1}$, Zohreh Dalirsani ${ }^{1}$, Atessa Pakfetrat ${ }^{1}$, Ali Falaki ${ }^{2}$, Nasrollah Saghravanian ${ }^{3}$, Tahereh Nos- \\ ratzehi $^{4}$, Mahdi Pazouki ${ }^{5}$
}

\footnotetext{
${ }^{1}$ Assistant Professor of Oral Medicine, Dental Research Center of Mashhad University of Medical Sciences, Department of Oral Medicine of Mashhad Dental School, Mashhad, Iran

2 22nd Bahman hospital, Azad University of Medical Sciences, Mashhad, Iran

${ }^{3}$ Assistant Professor of Oral and Maxillofacial Pathology, Dental Research Center of Mashhad University of Medical Sciences, Department of Oral and Maxillofacial Pathology of Mashhad Dental School, Mashhad, Iran

${ }^{4}$ Postgraduate student of Oral Medicine, Department of Oral Medicine of Mashhad Dental School, Mashhad, Iran

${ }^{5}$ Dental student, Department of Oral Medicine of Mashhad Dental School, Mashhad, Iran
}

Correspondence:

Dental Research Center of Mashhad,

University of Medical Sciences,

Department of Oral Medicine,

Mashhad Dental School,

Vakilabad Blvd,

91735 Mashhad, Iran

zdalirsani@gmail.com

Falaki F, Dalirsani Z, Pakfetrat A, Falaki A, Saghravanian N, Nosratzehi T, Pazouki M. Clinical and histopathological analysis of oral Squamous cell carcinoma of young patients in Mashhad, Iran: A retrospective study and review of literatures Med Oral Patol Oral Cir Bucal. 2011 Jul 1;16 (4):e473-7.

http://www.medicinaoral.com/medoralfree01/v16i4/medoralv16i4p473.pdf

Received: $22 / 02 / 2010$

Accepted: 31/05/2010

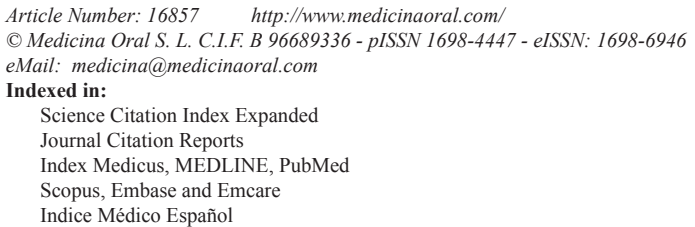

\begin{abstract}
Objectives: Oral Squamous cell carcinoma (OSCC) is primarily a disease that mainly occurs in males in their sixth and seventh decades of life and is rare in young adults.

Study Design: In this retrospective study, records of patients under the age of 40, with the diagnosis of OSCC in the Oral Medicine Department of Mashhad Dental Faculty during the past 13 years were analyzed. Their socioeconomic data, demographic, clinical and histopathological characteristics, risk factors, familial history were assessed and applicable studies and case reports in the literatures were reviewed. PCR (Polymerase chain reaction) analysis was also done for detection of human papilloma virus (HPV).

Results: From 158 cases of OSCC diagnosed in our centre, 21 patients were younger than 40 years. Most of them were young men (12 cases). There was no significant risk factor in this group. The most common site of involvement was the tongue. The most common clinical presentation was exophytic lesion with ulcer. No HPV DNA was detected in these patients.

Conclusion: Characteristics of OSCC in young patients are different from older age group. Major risk factors (smoking and alcohol consumption and HPV) were not etiologic factors for OSCC in young patients in our province.
\end{abstract}

Key words: Oral squamous cell carcinoma, oral cancer, young patients, risk factors, Iran, retrospective study. 


\section{Introduction}

Oral squamous cell carcinoma (OSCC) of head and neck is a major health problem world wide that usually appears in patients older than 50 years of age. Several studies showed that between 1 to 6 percent of oral cancers have been presented in patients under the age of $40(1-3)$

Although there has been a declining trend in the overall incidence of OSCC, the incidence in young adults seems to be increasing worldwide $(2,3,4-6)$.

It seems that biological behavior and etiology of OSCC in young patients are unlike older age groups and some studies suggest that oral cancer in young patients is more aggressive (6). Recent studies revealed that there is no difference between clinical course and survival rate $(2,7-9)$.

Iran is a large country located in the Middle East and Khorasan is one of the largest provinces in Iran covering $7.8 \%$ of the total area of this country. This province has a population of about 7 millions and is located in the northeast of Iran.

The purpose of conducting this study was to obtain the socioeconomic data and to analyze the clinical and pathological findings of OSCC in young patients in our centre.

\section{Material and Methods}

This is a retrospective study based on the records of the patients in the archive of Oral Medicine and Oral Pathology Department of Mashhad dental Faculty. Twenty-one cases of OSCC have been diagnosed in young patients in our center from 1996 to 2009. Demographic data and clinical features were recorded upon archive of Oral Medicine Department and histopathological characteristics were obtained from Oral Pathology Department of our centre.

These Departments receive nearly most of the oral pathology specimens from private and public hospitals and clinics throughout the entire province.

We divided the sites into the tongue, floor of mouth, buccal mucosa, alveolus and the gingiva. The World Health Organization classification was used to assess the histopathological type, and all specimens were tested for presence of HPV by using PCR analysis. Malignant neoplasm of major salivary glands was not included in this study. Only cases of primary oral cancers were considered in this report; no recurrent, in situ or benign lesions were included.

SPSS version 12.0 statistical software was used for data entry and analysis. Descriptive statistics such as mean and standard deviations (SD) was used for age. Frequency and percentages for gender, risk factors, sites, and biopsy were calculated.

\section{Results}

Sociodemographic data:

The total number of new malignant oral cancers for the period from 1996 to 2009 was 158 . Twenty-one cases of OSCC have been diagnosed in young patients. Fiftyseven percent of our patients were male (Male to female ratio was $1.3 / 1$ ) with an age range of 20-40 years (Mean age of 30.19; S.D. $=4.24$ years). The mean age for males and females was comparable. (Males: mean age of 30.25; $\mathrm{SD}=4.09$ years and females: mean age of $30.11 ; \mathrm{SD}=4.70$ years)

Sites:

The most common site of involvement was the tongue $(66 \%)$. Most of the tongue SCCs involved the lateral border.

Risk factors:

No major risk factor were found in the patients and they were all healthy, only in one case there was a history of gastric bypass because of overweight, performed one year before appearance of the lesion. None of the patients had familial history of cancer.

Clinical feature:

The most common clinical presentation was exophytic lesion with ulcer, but some rare features like odontogenic SCC (in one patient) or exophytic SCC with smooth and intact surface (in two patients) were also observed. Duration of the lesions in our patients ranged from 2 weeks to 7 months.

The main clinical findings are summarized in (Table $1)$.

\section{Histopathology:}

Histopathological examination revealed that most of the tumors were well differentiated. No poorly differentiated SCC was detected in our patients. HPV was not found in our samples.

\section{Discussion}

Oral cancer is one of the ten most common cancers in our province (10). Although the incidence of OSCC in patients less than 40 is low, we encountered 21 cases out of a total number of 158 cases (13\%) in Mashhad Dental Faculty during a 13 years period (from 1996 to 2009). Similar studies in Iran showed approximately the same results; ranging $11 \%-15 \%$ of patients in Shiraz and Tehran and $21.6 \%$ in Kerman (10-12).

Oral cancer is predominantly a disease of men in all age groups $(2,3)$ as we noticed in our study, but some studies revealed a female predilection in young patients with $\operatorname{OSCC}(4,6)$.

The most common site of involvement was the tongue. It was compatible with other studies in Iran (10-12) and the study of Sasaki et al. (UK) (2) and Siriwardena (Sri Lanka) et al. (4) and in contrast to some other Asian countries such as Thailand, Taiwan and India, which buccal mucosa was the most common site of involve- 
Table 1. Characteristics of 21 patients with OSCC (M: Male, F: Female).

\begin{tabular}{|c|c|c|c|c|c|c|}
\hline No. & Age & Sex & Location & Clinical feature & Grade & Duration \\
\hline 1 & 35 & $\mathrm{~F}$ & Tongue & Exophytic lesion\&ulcer & 2 & 3 months \\
\hline 2 & 31 & M & Posterior mandibular ridge & Exophytic lesion & 2 & 2 weeks \\
\hline 3 & 38 & $\mathrm{~F}$ & Tongue & Ulcer & 1 & 4 months \\
\hline 4 & 31 & $\mathrm{~F}$ & Maxilla & Exophytic lesion & 1 & 1 month \\
\hline 5 & 35 & M & Tongue & Exophytic lesion & 1 & 2 months \\
\hline 6 & 24 & $\mathrm{~F}$ & Tongue & Exophytic lesion & 2 & 3 weeks \\
\hline 7 & 29 & M & Posterior mandibular vestibule & Exophytic lesion & 1 & 1 month \\
\hline 8 & 20 & M & Posterior mandibular ridge & Exophytic lesion & 1 & 25 days \\
\hline 9 & 32 & M & Tongue & Exophytic lesion & 1 & 1.5 months \\
\hline 10 & 24 & $\mathrm{~F}$ & Tongue & Ulcer & 2 & 7 months \\
\hline 11 & 28 & $\mathrm{~F}$ & Tongue & Ulcer & 1 & 3 months \\
\hline $12 *$ & 29 & $\mathrm{~F}$ & Tongue & White Plaque & 1 & 1 month \\
\hline 13 & 29 & M & Tongue & Exophytic lesion & 1 & 2 weeks \\
\hline 14 & 35 & M & Posterior mandibular ridge & Exophytic lesion & 1 & 3 months \\
\hline 15 & 29 & $\mathrm{~F}$ & Tongue & Exophytic lesion\&ulcer & 3 & 2 months \\
\hline 16 & 31 & M & Tongue & Exophytic lesion\&ulcer & 1 & 1 month \\
\hline 17 & 33 & $\mathrm{~F}$ & Tongue & Exophytic lesion\&ulcer & 1 & 2 months \\
\hline 18 & 27 & M & Tongue & Ulcer & 2 & 2 weeks \\
\hline 19 & 31 & M & Buccal mucosa & Exophytic lesion\&ulcer & 1 & 7 months \\
\hline 20 & 29 & $\mathrm{M}$ & Tongue & Exophytic lesion\&ulcer & 1 & 2 months \\
\hline 21 & 34 & $\mathrm{M}$ & Lip & Ulcer & 1 & 1 month \\
\hline
\end{tabular}

* Patient with history of gastric bypass. 
Table 2. Summary of studies and cases reporting OSCC in patients between 20 and 45 years of age in the English literature cited.

\begin{tabular}{|c|c|c|c|c|c|c|c|c|}
\hline & $\begin{array}{c}\text { No. of } \\
\text { patients }\end{array}$ & Years & $\begin{array}{c}\text { Sex } \\
(M / F)\end{array}$ & Age & Site* & $\begin{array}{c}\text { Stage } \\
* *\end{array}$ & $\underset{* * *}{\mathbf{G}}$ & Country \\
\hline Siriwardena et al (4) & 56 & $1996-2001$ & $45 / 11$ & Under 40 & $\mathrm{~T}$ & & & Sri Lanka \\
\hline Manuel et al (14) & 76 & $1990-94$ & $48 / 28$ & $20-45$ & $\mathrm{~T}$ & III/IV & W & India \\
\hline Lype et al (9) & 115 & $1982-96$ & $74 / 41$ & Less 35 & $\mathrm{~T}$ & III/IV & $\mathrm{W}$ & India \\
\hline Ho et al (8) & 28 & $1999-2005$ & $27 / 1$ & $27-45$ & B & $\mathrm{I} / \mathrm{II}$ & & Taiwan \\
\hline Llewellyn et al(3) & $116(6 \%)$ & $1990-97$ & $65 / 51$ & $20-45$ & $\mathrm{~T}$ & $\mathrm{I} / \mathrm{II}$ & & UK \\
\hline Pitman et al (7) & 122 & $1982-94$ & $70 / 52$ & $16-39$ & $\mathrm{~T}$ & $\mathrm{I} / \mathrm{II}$ & & US \\
\hline Kuriakose et al (6) & $37(1.8)$ & $1988-90$ & $17 / 20$ & $21-34$ & $\mathrm{~T}$ & III & $\mathrm{W}$ & India \\
\hline Sasaki et al (2) & $35(6 \%)$ & 1990-99 & $20 / 15$ & $20-40$ & $\mathrm{~T}$ & I & W & UK \\
\hline Iamaroon et al(5) & $75(12.8 \%)$ & $1991-2000$ & $\mathrm{M}>\mathrm{F}$ & $<45$ & $\mathrm{~T}$ & IV & $\begin{array}{c}\mathrm{M} \text { to } \\
\mathrm{W}\end{array}$ & Thailand \\
\hline Hirota et al (1) & $13(10.7 \%)$ & 1994-2004 & $8 / 5$ & $20-40$ & $\mathrm{~T}$ & & & Brazil \\
\hline Chitapanarux et al(19) & 18 & $1999-2003$ & $10 / 8$ & $20-40$ & $\mathrm{~T}$ & III,IV & $\mathrm{W}$ & Thailand \\
\hline Braakhuis et al (18) & $6 \%$ & $1989-2006$ & $442 / 138$ & Less 40 & $\mathrm{~T}$ & I & & Netherland \\
\hline Chidzonga et al (20) & $46(12.8 \%)$ & $1982-91$ & $26 / 20$ & $20-40$ & $\mathrm{~F}$ & & $\mathrm{~W}$ & Zimbabwe \\
\hline Falaki et al & $21(13 \%)$ & 1996-2009 & $12 / 9$ & $21-38$ & $\mathrm{~T}$ & & $\mathrm{~W}$ & Iran \\
\hline
\end{tabular}

ment. This difference seems to be related to different habits $(5,12)$.

None of our cases had a special risk factor or habit. It was consistent with some previous studies, whereby no major risk factor (smoking and/or drinking) were present $(3,8)$.

Low alcohol consumption due to Islamic rules, and risky behaviors among people of this province such as chewing tobacco and eating spicy foods might explain showing no risk factor in our cases.

The study of Llewellyn et al in south east of England showed that $25 \%$ of young patients had no usual risk factor (3).

Familial history has been suggested as an important etiological factor in young people. Some researchers believe that familial history is more significant than tobacco and alcohol consumption in developing of OSCC in the young $(1,8)$.

Viral infections (13), deficiency of fresh fruits and vegetables in diet (14) nutritional deficiencies (particularly of iron and folic acid) (15), have been suggested as the risk factors of OSCC in young people in the literature. In this research there were no evidence of family history or HPV infection in our cases, but an interesting finding was a history of gastric bypass because of over weight in patient No.12, done one year before OSCC presentation. To the best of our knowledge it is the first report of such finding.

Patients undergoing mal-absorptive weight-loss procedures such as gastric bypass are at increased risk of calcium, vitamin D, copper and iron deficiency which is predisposing factors for anemia, neutropenia, and leukopenia (15). These conditions have been suggested as predisposing factors for OSCC (15).

The most common clinical presentation of OSCC in our patients was exophytic lesion, but in the study of kuriakose et al. and Manuel et al. ulceroproliferative lesions were more common $(6,14)$. This may be related to different habits of different cultures.

We noticed two extremely rare presentations of OSCC, raised lesion with smooth and intact surface and one case of primary intraosseous odontogenic carcinoma (PIOC) in our cases (three out of 20; $15 \%$ of cases).

One lesion was located in the tongue of a 31-year old man and the other in the buccal mucosa of a 29-year old woman. We didn't find any similar reports in the literature; only one case of OSCC with smooth surface was reported in the buccal mucosa of a 75- year old woman (16). 
PIOC in our patient was derived from a keratocystic odontogenic tumor and perforated the cortex of bone which is extremely rare for this lesion and was reported in the literature before (17).

There is a major controversy about the prognosis and clinical course of OSCC between young and old patients in the literature. Sasaki et al. believed that there are minimal differences between the younger and the older patients in clinical and histological characteristics (2). But other studies have reported fewer recurrences and distant metastasis and better survival rate in the young patient population (8).

Histopathological examination revealed probable better prognosis ( SCC grade 1) in most of our patients. It is in agreement with the literature $(6,14)$ however ,some authors believe that oral cancer in young adults has more aggressive behavior and poorer prognosis and some other studies showed similar survival among younger and older patients $(6,7)$.

Late diagnosis and treatment of OSCC will result in severe debilitation due to mutilating surgery, often associated with extensive destruction of oral and facial structures, so early diagnosis and proper management is needed to achieve a better quality of life and higher survival rate. Although OSCC is rare in young people and may be misdiagnosed or neglected by both medical and dental practitioners and patients themselves, fortunately, most of our cases were diagnosed in stage 1 and lead to a better prognosis. Report of such cases and their clinical features may help scientists to find other possible predisposing factors, to better understand the biologic behavior of tumor, which will finally lead to an increase in the awareness and experience of the clinicians and patients, as well.

Characteristics of OSCC in younger age groups according to the literatures are summarized in (Table 2).

More future studies in large populations should be done to achieve a reliable and definite conclusion about the nature of OSCC in young patients, its etiology and risk factors and to determine whether OSCC in these patients have a worse prognosis and warrant more aggressive treatment.

\section{References}

References with links to Crossref - DOI

1. Hirota SK, Migliari DA, Sugaya NN. Oral squamous cell carcinoma in a young patient - Case report and literature review. An Bras Dermatol. 2006;81:251-4.

2. Sasaki T, Moles DR, Imai Y, Speight PM. Clinico-pathological features of squamous cell carcinoma of the oral cavity in patients $<40$ years of age. J Oral Pathol Med. 2005;34:129-33.

3. Llewellyn CD, Johnson NW, Warnakulasuriya KA. Risk factors for oral cancer in newly diagnosed patients aged 45 years and younger: a case-control study in Southern England. J Oral Pathol Med. 2004;33:525-32.

4. Siriwardena BS, Tilakaratne A, Amaratunga EA, Tilakaratne WM. Demographic, aetiological and survival differences of oral squamous cell carcinoma in the young and the old in Sri Lanka. Oral Oncol. 2006;42:831-6.
5. Iamaroon A, Pattanaporn K, Pongsiriwet S, Wanachantararak S, Prapayasatok S, Jittidecharaks S, et al. Analysis of 587 cases of oral squamous cell carcinoma in northern Thailand with a focus on young people. Int J Oral Maxillofac Surg. 2004;33:84-8.

6. Kuriakose M, Sankaranarayanan M, Nair MK, Cherian T, Sugar AW, Scully C, et al. Comparison of oral squamous cell carcinoma in younger and older patients in India. Eur J Cancer B Oral Oncol. 1992;28B:113-20.

7. Pitman KT, Johnson JT, Wagner RL, Myers EN. Cancer of the tongue in patients less than forty. Head Neck. 2000;22:297-302.

8. Ho HC, Lee MS, Hsiao SH, Hwang JH, Hung SK, Chou P, et al. Squamous cell carcinoma of the oral cavity in young patients: a matched-pair analysis. Eur Arch Otorhinolaryngol. 2008;265 Suppl 1:S57-61.

9. Iype EM, Pandey M, Mathew A, Thomas G, Sebastian P, Nair MK. Oral cancer among patients under the age of 35 years. J Postgrad Med. 2001;47:171-6.

10. Mousavi SM, Gouya MM, Ramazani R, Davanlou M, Hajsadeghi $\mathrm{N}$, Seddighi Z. Cancer incidence and mortality in Iran. Ann Oncol. 2009;20:556-63.

11. Sargeran K, Murtomaa H, Safavi SM, Vehkalahti M, Teronen O. Malignant oral tumors in iran: ten-year analysis on patient and tumor characteristics of 1042 patients in Tehran. J Craniofac Surg. 2006; $17: 1230-3$

12. Andisheh-Tadbir A, Mehrabani D, Heydari ST. Epidemiology of squamous cell carcinoma of the oral cavity in Iran. J Craniofac Surg. 2008;19:1699-702.

13. Scully C. Oral cancer; the evidence for sexual transmission. $\mathrm{Br}$ Dent J. 2005;199:203-7.

14. Manuel S, Raghavan SK, Pandey M, Sebastian P. Survival in patients under 45 years with squamous cell carcinoma of the oral tongue. Int J Oral Maxillofac Surg. 2003;32:167-73.

15. Varma S, Baz W, Badine E, Nakhl F, McMullen H, Nicastro J, et al. Need for parenteral iron therapy after bariatric surgery. Surg Obes Relat Dis. 2008;4:715-9.

16. Falaki F, Delavarian Z, Pakfetrat A, Mohtasham N, Shirazian S. Oral Squamous cell carcinoma with an unusual clinical manifestation: a case report. Cases J. 2009;2:6608.

17. Falaki F, Delavarian Z, Salehinejad J, Saghafi S. Squamous cell carcinoma arising from an odontogenic keratocyst: a case report. Med Oral Patol Oral Cir Bucal. 2009;14:E171-4.

18. Braakhuis BJ, Visser O, Leemans CR. Oral and oropharyngeal cancer in The Netherlands between 1989 and 2006: Increasing incidence, but not in young adults. Oral Oncol. 2009;45:e85-9.

19. Chitapanarux I, Lorvidhaya V, Sittitrai P, Pattarasakulchai T, Tharavichitkul E, Sriuthaisiriwong P, et al. Oral cavity cancers at a young age: analysis of patient, tumor and treatment characteristics in Chiang Mai University Hospital. Oral Oncol. 2006;42:83-8.

20. Chidzonga MM, Mahomva L. Squamous cell carcinoma of the oral cavity, maxillary antrum and lip in a Zimbabwean population: a descriptive epidemiological study. Oral Oncol. 2006;42:184-9. 